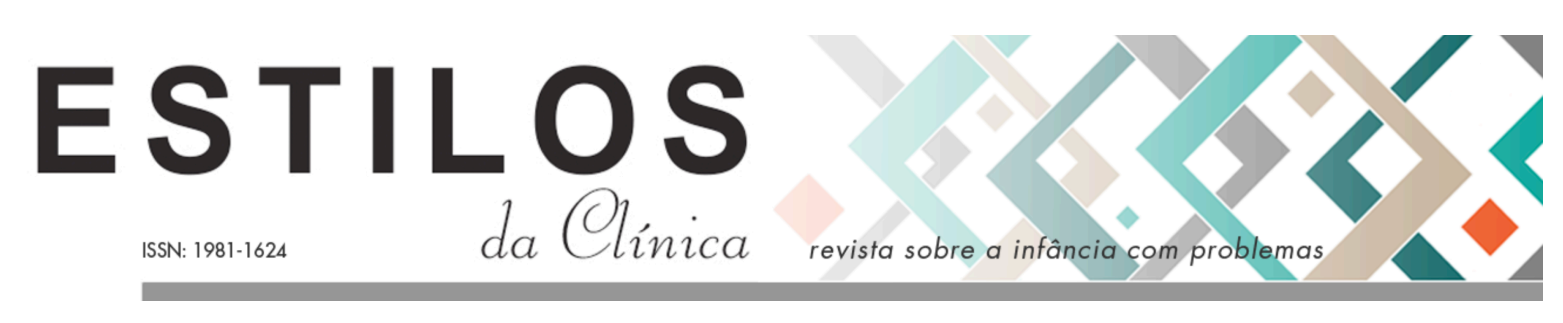

DOI: https://doi.org/10.11606/issn.1981-1624.v26i3 p445-460.

\title{
Dossiê
}

\section{Dissolução da adoção: (des)encontros entre maternidade e filiação}

\author{
Jussara Glória Rossato; Eduarda Lima de Oliveira; Vera Regina Röhnelt Ramires; \\ Denise Falcke
}

Resumo. A adoção é um processo complexo, que nem sempre terá um desfecho bem sucedido. A partir de um estudo de caso, objetivou-se compreender as experiências de uma mulher, mãe por adoção de cinco filhos, que vivenciou a dissolução da adoção. A filha mais velha solicitou o retorno para a instituição de acolhimento, após sete anos de convivência com a família adotiva. Os dados foram obtidos pela construção do genograma e entrevista semiestruturada com a mãe. Na visão da participante, a dificuldade na constituição de vínculos afetivos entre mãe e filha levou à dissolução da adoção, associada ao não acesso ao acompanhamento profissional no período pósadoção. Discute-se a questão da irrevogabilidade da adoção, a aplicabilidade dos termos devolução e duplo abandono e a importância da rede de apoio.

Palavras chave: adoção; dissolução; formação de vínculos; parentalidade adotiva.

\section{Disolución de la adopción: (des)encuentros entre maternidad y afiliación}

Resumen. La adopción es un proceso complejo y no siempre tendrá un resultado exitoso. A partir de un estudio de caso, el objetivo fue comprender vivencias de una mujer, madre por adopción de cinco hijos, que vivió la disolución de la adopción. La hija mayor solicitó el regreso luego de siete años de convivir con la familia por adopción. Los datos se obtuvieron mediante la construcción del genograma y la entrevista semiestructurada con la madre. A juicio de la participante, la dificultad para formar vínculos afectivos entre madre e hija llevó a la disolución de la adopción, asociada a falta de acceso a seguimiento profesional en período pos-adopción. Fueran discutidos aspectos de irrevocabilidad de la adopción, la aplicabilidad de los términos retorno y doble abandono y importancia de red de apoyo.

Palabras clave: adopción; disolución; formación de enlaces; crianza adoptiva.

\footnotetext{
* Doutora em Psicologia Clínica, Universidade do Vale do Rio dos Sinos, São Leopoldo, RS, Brasil. E-mail: ju_psicologia@yahoo.com.br

** Doutoranda em Psicologia Clínica, Universidade do Vale do Rio dos Sinos, São Leopoldo, RS, Brasil. Email: dulimaoliv@gmail.com

*** Professora da Pós-Graduação em Psicologia Clínica, Universidade do Vale do Rio dos Sinos, São Leopoldo, RS, Brasil. E-mail: vramires@unisinos.br

**** Professora da Pós-Graduação em Psicologia Clínica, Universidade do Vale do Rio dos Sinos, São Leopoldo, RS, Brasil. E-mail: dfalcke@unisinos.br
} 


\title{
Dissolution in Adoption: (dis)encounters between motherhood and sonship
}

\begin{abstract}
Adoption is a complex process and will not always have a successful outcome. From a case study, the objective was to understand the experiences of a woman, a mother by adoption of five children, who experienced the dissolution of adoption. The eldest daughter requested the return to foster care after seven years of living with the adoptive family. The data were obtained by constructing the genogram and semi-structured interview with the mother. According to the participant, the difficulty in establishing affective bonds between mother and daughter led to the dissolution of the adoption, associated with the lack of access to professional monitoring in the postadoption period. Questions on the indissolubility of the adoption, the terminology used and the importance of the support network were discussed.
\end{abstract}

Keywords: adoption; dissolution; bonding; adoptive parenting.

\section{Dissolution de l'adoption: (dis)rencontres entre la maternité et l'affiliation}

Résumé. L'adoption est un processus complexe qui n'aura pas toujours de succès. À partir d'une étude de cas, l'objectif était comprendre les expériences d'une femme, mère adoption de cinq enfants, qui vécu la dissolution de l'adoption. Dans cas, la fille aînée qui a demandé ce retour après sept ans vie avec la famille adoption. Les données ont obtenues en construisantgénogramme et en entretien semi-structuré avec la mère. Il a été constaté que, l'avis du participant, la difficulté à nouer liens affectifs entre la mère et la fille entraînait la dissolution de l'adoption, associée au manque d'accès au suivi professionnel dans la période post-adoption. En conséquence, il a été possible de problématiser certains aspects de l'irrévocabilité de l'adoption, l'applicabilité des termes retour et double abandon et l'importance du réseau de soutien.

Mots-clés: adoption; dissolution; liaison; parentalité adoptive.

A adoção representa o encontro de pessoas que possuem desejos quanto à formação de laços familiares (Muniz, 2016). Além disso, é um ato afetivo e jurídico (Queiroz \& Passos, 2012). No Brasil, após o estabelecimento da guarda definitiva esse processo é compreendido como irrevogável (Brasil, 1990). Todavia, um estudo realizado na cidade de Recife, no período de 2009 a 2015, identificou 35 casos de "devolução", envolvendo 24 crianças e adolescentes, o que representa uma "devolução" a cada dois meses (Muniz, 2016).

A literatura nacional tem denominado o retorno de crianças e adolescentes às instituições de acolhimento após adoção como "devolução" (Levinzon, 2006; Schettini, Amazonas, \& Dias, 2006); contudo, neste trabalho, optou-se por utilizar o termo dissolução da adoção, ainda que, no decorrer do artigo, foi mantida a terminologia utilizada pelos autores citados. Mesmo que não haja uma previsão legal para a ocorrência da dissolução da adoção, entende-se que a nomenclatura "devolução" traz uma perspectiva de coisificação e um centramento na figura da criança, que deve ser evitado, considerando que é frequente atribuir o insucesso da adoção a características dela (Campidelli \& Bertoncini, 2018; Carnaúba \& Ferret, 2018; Levy, Pinho, \& Faria, 2009; Muniz, 2016; Santos, 2018; Souza \& Casanova, 2018), tais como idade na adoção (Faulkner, Adkins, Fong, \& Rolock, 2017; Paniagua, Palacios, \& Jiménez-Morago, 2019), problemas emocionais e de comportamento (Faulkner et al., 2017; Rosnati, Ranieri, \& Ferrari, 2017; White, 2016) e número de passagens por lares adotivos (Rolock \& White, 2016; Selwyn, Wijedasa, \& Meakings, 2014). No Brasil, são escassos os estudos sobre o fenômeno (Rossato \& Falcke, 2017), possivelmente por não haver previsão legal para a ocorrência da dissolução da adoção (Brasil, 1990; Brasil, 2009). Entretanto, não é possível negar a ocorrência do fenômeno e as inúmeras consequências a todos os envolvidos: adotados, adotantes e componentes das equipes de suporte (Palacios, Rolock, Selwyn, \& Barbosa-Ducharne, 2019). 
A construção da parentalidade e filiação adotivas é complexa. Tem-se, por um lado, uma criança ou adolescente que carrega um histórico biológico e social, muitas vezes com marcas de rupturas traumáticas, rejeições e abandonos (Machado, 2014). Por outro lado, há uma família disposta a acolher, que também passa por um processo adaptativo e necessita criar, juntamente com o recém-chegado, um ambiente psíquico saudável para o exercício da parentalidade. Essa transição é carregada de constantes processos de transformação, para que se configure uma nova organização psíquica, evolvendo diversos lutos (Junqueira, 2014).

A chegada de um filho produz uma mudança no psiquismo parental. As funções materna e paterna irão auxiliar na construção psíquica da criança ou adolescente, que, além de alcançar o reconhecimento de sua filiação, recebe também um lugar de pertencimento nessa ambiência familiar (Zornig, 2010). No caso da adoção, a construção da parentalidade passa pelo estágio de convivência. Nesse período, tanto os futuros pais como a criança ou adolescente têm o acompanhamento da equipe técnica. Quando a vinculação afetiva não acontece, a adoção não se concretiza e a criança ou o adolescente permanecem ou retornam para a instituição de acolhimento. Esse procedimento está previsto como possível de ser realizado antes de ser efetivada a adoção. Mesmo quando ocorre nesse período, a literatura salienta que essa ruptura pode promover sofrimento psíquico (Souza \& Casanova, 2018). Todavia, a dissolução da adoção, quando acontece após a finalização do processo, constitui-se em um processo doloroso de ser vivenciado, com consequências ainda mais difíceis para todos (Muniz, 2016).

É necessário atentar-se para as repercussões psíquicas nas crianças/adolescentes, que podem reeditar o trauma do abandono, quanto nos adultos, visto que os efeitos resultantes do insucesso em um projeto adotivo trarão implicações também na sua vida, como sentimento de impotência, culpa e fracasso (Araújo, 2017; Ghirardi, 2008a; Souza \& Casanova, 2018). Estudos têm apontado que o fracasso em processos adotivos pode resultar de motivações subjetivas dos pais para a adoção, tendo como pano de fundo a imagem de um filho idealizado que difere de um filho possível (Costa, Bortoli, \& Severo, 2019; Ghirardi, 2008b; Levinzon, 2006; Schettini et al., 2006; Zornig, 2010). Nesse contexto, os casos de dissolução da adoção podem ocorrer quando não foram trabalhados os conflitos psíquicos ocultos relacionados às origens da busca pelo filho por adoção (Ghirardi, 2008a).

As motivações inconscientes expressas pelos sujeitos que desejam a parentalidade devem ser avaliadas (Levy et al., 2009; Machado, 2014; Palacios, Jiménez-Morago, \& Paniagua, 2015). Dificuldades vivenciadas pelos adotantes também podem estar associadas às frustrações, aos entraves na via dupla de constituição de vínculo e ao sentimento de incapacidade parental para lidar com as demandas exigidas por uma criança/adolescente (Morelli, Scorsolini-Comim, \& Santeiro 2015), alertando para o quanto os pais por adoção devem se preparar para a parentalidade. Esse processo envolve, além da aquisição de informações, a disponibilidade para a construção da relação parento/filial e a existência de uma rede de apoio.

Silva (2008) argumenta que, na maioria das vezes, os adotantes atribuem os problemas vivenciados na adoção à família de origem da criança, colocando o filho por adoção como principal causador, minimizado as razões socioculturais, o que, de certa forma, visa eximi-los de responsabilidades quanto ao desfecho de uma adoção malsucedida. Já, para Araújo (2017), o fracasso na adoção pode ocorrer quando a inserção de uma criança na família não encontra o lugar de pertencimento, o que pode ser potencializado no caso de crianças mais velhas.

A literatura ainda é muito escassa de estudos que deem voz aos adultos que adotaram e vivenciaram a dissolução da adoção. Uma pesquisa realizada com uma mulher que adotou e desistiu da adoção em Salvador revelou que a família enfrentou dificuldades para inserir essa 
criança na condição de filho. As repercussões emocionais se fizeram com dor e sofrimento, que só tiveram alívio após a criança ter sido adotada por outra família (Araújo, 2017). Speck, Queiroz e Martin-Mattera (2018) também ouviram um casal que devolveu um filho adotivo em Pernambuco e relataram que a impossibilidade da adotada de superar seu passado de rejeição dificultou a construção do vínculo, o que parece ter sido determinante para o desfecho.

Dessa maneira, é indispensável atentar para todo o contexto que circunda a adoção, em especial no que diz respeito à formação de vínculos que poderão ou não ser construídos. Nesse sentido, conhecer a experiência de todos envolvidos é essencial. O presente estudo busco dar voz a uma mulher, mãe por adoção, que vivenciou a dissolução da adoção de uma adolescente.

\section{Método}

Trata-se de uma pesquisa com enfoque qualitativo, transversal (Creswell \& Clark, 2013) e delineamento de estudo de caso único (Yin, 2001). O estudo de caso único é o método de escolha quando se pesquisa uma condição rara ou extrema (Yin, 2001), como pode ser considerada a dissolução da adoção. Foi utilizado o Consolidated Criteria for Reporting Qualitative Research (COREQ) como critério para a descrição dos dados do estudo. Ele consiste em uma lista de verificação (checklist) empregada em estudos qualitativos com o objetivo de auxiliar na descrição detalhada dos passos utilizados na pesquisa.

\section{Participante}

Participou desta pesquisa uma mulher, mãe por adoção de cinco filhos, que desistiu da adoção de uma das filhas, após sete anos de convivência familiar. A participante, identificada como Lucia (nome fictício), tinha 46 anos, era do sexo feminino, residia na Europa, possuía terceiro grau incompleto, era do lar e estava divorciada.

\section{Instrumentos}

Utilizou-se a entrevista semiestruturada, tendo em vista favorecer a exploração profunda das experiências vividas pela participante nos processos de adoção e dissolução. A entrevista foi pautada em uma pergunta norteadora ou disparadora, seguindo um roteiro flexível e aberto, sensível aos diferentes modos de reação da entrevistada. Também foi realizada a construção do genograma familiar, que possibilita a representação gráfica das relações familiares (Nichols \& Schwartz, 1998).

\section{Procedimentos éticos e coleta de dados}

Esta pesquisa seguiu as recomendações éticas e as orientações da Resolução n. 510/2016 do Conselho Nacional de Saúde. O projeto foi aprovado pelo Comitê de Ética em Pesquisa da Universidade sob parecer 2.378.496 e a participante assinou o Termo de Consentimento Livre e Esclarecido (TCLE). Para a coleta de dados, foram contatados o Juizado da Infância e 
Juventude e as Varas da Infância e Juventude do Sul do Brasil, os profissionais da rede da adoção, a Associação Nacional de Grupos de Apoio à Adoção, os Grupos de apoio à Adoção de todo o Brasil e as Casas Lares e instituições de acolhimento da região, visando averiguar a existência e possibilidade de contato com pessoas envolvidas em casos de dissolução da adoção. Após as indicações, foram realizados 47 convites para participação, sendo negados 46 .

O contato com a participante e a entrevista foram realizados pela primeira autora deste estudo. Em concordância com a participante, a entrevista foi realizada por Skype, com duração de duas horas, sendo gravada em áudio. O conteúdo foi transcrito na íntegra para posterior leitura e análise.

\section{Procedimentos de análise dos dados}

A partir das informações obtidas por meio das entrevistas e do genograma, a análise de dados foi baseada no procedimento proposto por Yin (2001), que consiste em cinco elementos para a interpretação dos dados. Inicialmente, a partir da questão do estudo, seguiu-se as proposições de análise teóricas (Yin, 2001), de acordo com os seguintes passos: descrição do caso, de maneira cronológica e temática, e desenvolvimento da explanação, detalhando exaustivamente as informações do caso e construindo uma explanação abrangente, articulada aos pressupostos do referencial teórico, buscando articulação entre os dados clínicos com a literatura prévia.

\section{Resultados}

O genograma (Figura 1) ilustra a família de Lucia, destacando que ela e o ex-marido (Francisco) adotaram cinco crianças, sendo quatro de um mesmo grupo de irmãos. Ela mora fora do Brasil com três filhos, e o ex-marido reside em um estado do sul do Brasil com uma filha. A adolescente de 15 anos, aqui chamada Julia, retornou à instituição de acolhimento há um ano, após sete anos de permanência na família adotiva. Na ocasião da entrevista, fazia seis meses que Francisco retornara ao Brasil após a separação do casal. 


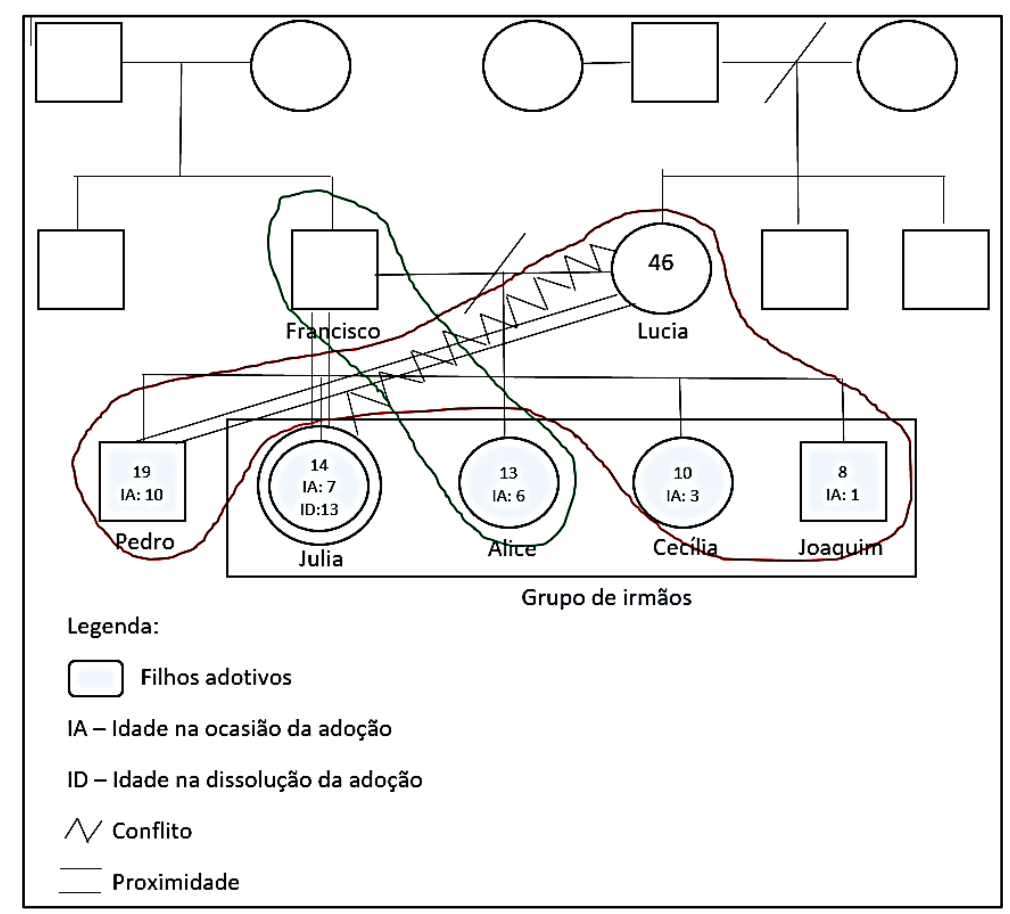

Figura 1. Genograma

Ao relatar sua história familiar, Lucia designa como "normal" sua infância e adolescência junto a sua família de origem. Comenta que os pais se separaram após 35 anos de convivência: "Tudo muito tranquilo dentro do modelo tradicional". Lucia é a filha mais velha de três irmãos: "Eu era uma menina curiosa, gostava de coisas novas, fui morar sozinha em Porto Alegre com 16 anos". Destaca que nunca foi muito estudiosa, mas gostava de aprender. Segundo ela, sempre teve acompanhamento psicológico "nos momentos delicados".

Com relação à vida conjugal, refere que se casou com 34 anos. Após dois anos, ela e seu marido decidiram adotar um menino, após conhecê-lo em um abrigo. Lucia assegura que o desejo de adotar uma criança deu-se por uma escolha do casal, não sendo motivado pela impossibilidade de ter filhos biológicos: "Não foi assim, não conseguimos ter filhos então vamos adotar, que é o natural, né? Nós não, a gente teve vontade de ter um filho, buscou um abrigo e, no que nós conhecemos a realidade dos abrigos, aí nós decidimos então não ter biológico. Conhecemos um abrigo e lá o Pedro".

Lucia relata que Pedro tinha 10 anos, quase 11 quando foi adotado pelo casal. Refere com muita alegria que "é um alemão lindo". Após a vivência satisfatória da adoção de Pedro, ao completarem dois anos de convivência, decidiram por adotar uma criança pequena de até um ano e meio. A assistente social informou que havia uma criança que se encontrava disponível com 1 ano e 3 meses (Joaquim), mas que ele tinha três irmãs, que deveriam ser adotadas junto: uma de 3 anos (Cecília), uma de 6 anos (Alice) e a outra de 7 anos (Julia). Lucia complementa: "Nós ficamos curiosos, quisemos conhecer as crianças e fomos. Conhecemos as crianças e começamos uma aproximação que durou 15 dias. Foi aí que conhecemos 'o quarteto fantástico"”.

Ela expressa que, na época, tinha uma vida profissional exigente e como mãe de Pedro. Foi então que, no período de aproximação, manifestou à equipe de apoio sua insegurança em não dar conta de suas obrigações e mais quatro crianças. A assistente social "achou melhor eu não ficar com as crianças". Lucia afirma que "tiraram meus filhos de mim [...] foi um vazio quando eu voltei para casa sem eles”. Buscaram ajuda da promotoria, sem retorno, contudo, após 3 a 4 
meses, com o retorno de licença de uma psicóloga, ela quis conhecer o caso e entendeu que o casal poderia adotar. Segundo Lucia, o entendimento dessa profissional era "que a gente teria condições de ficar com as crianças". Refere que, com a mediação dessa psicóloga, iniciaram as negociações com o juiz e que "depois de um mês de entrevistas", ou seja, quatro meses depois do período de aproximação, conseguiram a guarda provisória. A partir daí, passou a combinar sua exigente rotina de trabalho e o cuidado das cinco crianças: "quase enlouqueci [...] São crianças com muita diferença de idade, a nossa casa era uma casa pequena, que comportava todos, mas era pequena" e acrescenta que o que facilitou foi que: "eles vieram do abrigo muito disciplinados, com horários [...] A psicóloga me disse: só segue a rotina que vai dar certo. E foi exatamente isso que eu fiz. Eu não tinha empregada, não tinha nenhuma pessoa para me ajudar, então foi o que eu realmente fiz [...] e tudo correu bem".

$\mathrm{Na}$ época, Lucia indica que o que mais a assustava eram "os contextos de família, da realidade que eles viviam e começaram a trazer para dentro de casa. [...] e aí é que começaram alguns probleminhas". Nesse ponto, a entrevistada sinaliza as primeiras dificuldades decorrentes do processo de adoção. De forma ainda mais significativa, por força de questões de saúde respiratória dos quatro novos filhos, resolveram mudar para uma cidade com melhores condições climáticas: "Eu tomei a decisão; [...] gerou mudança em tudo. Eu não tinha mais a minha mãe, a sogra, as pessoas que podiam me ajudar, então eu tomei a decisão de ficar em casa, que foi algo bem dolorido pra mim, deixar de ter a minha vida pessoal pra me tornar somente mãe".

A partir da dedicação total de Lucia aos filhos e com sua presença constante em casa, segundo ela, a filha mais velha começou a dar sinais de que algo não estava bem: "ela ameaçava o tempo todo. Eu não conseguia ter uma aproximação com as crianças. Era sempre uma coisa que tinha que disputar. Disputar em termos, porque ela disputava e eu nem sabia que eu estava disputando". Lucia relata o comportamento de Julia: "ela falava com os irmãos no quarto: se essa mãe não der certo, a gente fica com outra mãe, a gente consegue outra mãe". Conforme a percepção de Lucia, a disputa tinha por motivo o fato de Julia ter "assumido o papel de mãe no contexto de cuidar dos irmãos quando pequena. Quando eu comecei a cuidar dos irmãos, ela se sentiu muito ameaçada". Conta de sua confusão sobre o que estava acontecendo: "Ela manifestava algumas coisas que eram estranhas para mim, mas eu não sabia se era da idade, se era rejeição". Lucia buscou uma psicóloga para a filha, mas as dificuldades seguiram. Segundo Lucia, a profissional em questão "não tinha experiência com adoção". Ela acrescenta chorando: "nunca foi diagnosticado nada muito grave. Talvez a psicóloga também achasse que era exagero da minha parte...eu não sei”.

Lucia enfatiza que nunca houve um confronto aberto, mas muitas tentativas de Julia de ir embora com os irmãos e algumas atuações, como adicionar algo na comida do cachorro, deixando claro, pelo relato de Lucia, que queria matá-lo. Lucia lembra ter questionado: "Tu queria mesmo matar o cachorro?", ao que Julia teria respondido: "sim". Para ela, "tudo aquilo era muito frio...muito estranho".

Após um episódio em que Pedro quase foi assaltado, Lucia declara "eu comecei a pensar no futuro deles, porque eu teria que ter uma vida só para levar e buscar as crianças". O casal decide por mais uma mudança, para outro país. Instalados na Europa, a preocupação com a adaptação dos filhos à nova realidade logo se dissipou, pois, adaptaram-se rapidamente. Todavia, conforme Lucia, passou a emergir, até ficar totalmente claro, o descontentamento de Julia em relação ao convívio familiar: "Ela [Julia] também se adaptou muito bem, fez amigos e tal, só que chegou o momento em que ela disse que não queria mais morar conosco". Ao lembrar 
disso, Lucia irrompe em lágrimas e é necessário pausar a entrevista. Em seguida, volta a relatar que essa manifestação de Julia: "foi um choque [...] eu vou te falar que eu mais ou menos imaginava que ela fosse fazer isso, mas quando ela tivesse os seus 16 ou 17 anos. Não assim, com 11 para 12 anos". Acrescenta que o impacto dessa revelação foi ainda maior para o seu companheiro: "Pro Francisco foi um choque bem maior, pra ele era mais difícil enxergar tudo o que estava acontecendo. Eu já sinalizava que tinha uma coisa muito errada".

A opção para a resolução da situação foi a ida de Julia para um Colégio Interno. Lucia refere que apostavam no afastamento como a possibilidade de ela sentir saudade, de valorizar o que ela tinha junto à família e estimavam que iria querer voltar, "mas não". Depois de uns seis meses, Julia volta para casa por ocasião das férias escolares: "Foi nas férias que a gente sentiu que ela não estava bem, porque não falava com ninguém. Não era só comigo e nem com o Francisco. Não falava mais com os irmãos". Lucia reporta, ainda, de forma emocionada, que soube que Julia havia anunciado na escola sua intenção de se suicidar. Com isso, refere que decidiu recorrer à psicóloga do abrigo no Brasil, pois diz não ter encontrado profissional especializado em adoção no país onde residia. A profissional do abrigo a teria encaminhado para a psicóloga do Fórum e Julia, ao retornar para a escola, passa a ser atendida por essa psicóloga à distância. Após um tempo, conforme Lucia, a psicóloga fez contato com ela já com a seguinte pergunta: "tu estás preparada pra levar a Julia de volta pro abrigo? Eu disse que preparada eu não estava e perguntei o que a gente poderia fazer ainda, né?’.

Ela relata, então, como foi a audiência, no Brasil, em que foi decidida a volta de Julia para o abrigo. Tal descrição envolveu muitas pausas emocionadas. Lucia conta que ela ficou no exterior com os outros filhos e Francisco acompanhou Julia. A partir do relato dele, ela sinaliza que soube como Julia se portou: indiferente às referências da família e ansiosa para voltar para o abrigo. Comenta que Julia teria se apressado em pegar sua mochila para retornar à instituição de acolhimento: "O juiz até mandou ela voltar e disse: 'faz o favor de agradecer ao teu pai pelo que ele fez por ti?' E ela: 'Ah, sim. Obrigada, pai. E tchau'. E foi. Então, foi muito difícil”. Questionada sobre os sentimentos que vivenciou na dissolução da adoção, Lucia declara:

"Eu acho que é um sentimento de total impotência, de fracasso. Eu acho que são sentimentos que eu trabalhei na terapia, do medo de talvez perder todos. É difícil... Dá um medo da justiça solicitar todos. A sensação que a gente tem é de que eles nunca são nossos. Não sei se um pai biológico sente isso, mas o medo de perder eles, de ter vivido uma vida inteira enquanto eles estão conosco, né? Desses oito anos que eles estão conosco e, de repente, tu fracassou".

Lucia também se refere às preocupações com Julia vivendo no abrigo:

"E saber que ela está lá, que ela é minha filha, que ela tem o meu sobrenome, mas que eu não tenho contato. Eu não sei o que ela está comendo, o que ela tá fazendo. [...] Nós respeitamos a decisão dela, eu acredito que ela não entende. Mas eu acho que, pra nos preservar, também a gente evita muito o contato, porque ela age com muita indiferença conosco. Então, eu procurei... eu falo por mim... eu procuro me preservar... Então, às vezes que eu procuro falar, eu falo com a psicóloga e sempre me coloco à disposição".

Em uma avaliação geral sobre a sua relação com Julia, chorando bastante, Lucia sinaliza que não houve a construção de um vínculo entre mãe e filha: "Eu entendo que não é uma relação de mãe e filha como eu consegui com as outras crianças. Eu vejo que realmente a Julia não estava preparada pra isso, ela não estava preparada para uma adoção, ela não estava preparada pra chamar alguém de mãe". Lucia faz observações sobre o fato de Julia estar bem no abrigo, à vontade na escola e demarca novamente sua percepção do que motivou a não encontrar um lugar na família: "Quando não tem o contexto familiar de pai e mãe, ela fica à vontade. Mas eu 
acho que ela não elaborou a questão de se colocar como filha... até porque, até então, ela era a mãe".

Lucia ainda sintetiza sua vivência de insucesso na tentativa de firmar laços familiares com Julia, reportando-se a uma fala de seu ex-marido, após seu retorno da viagem em que entregou Julia à equipe de profissionais que a encaminharia de volta ao abrigo. De acordo com Lucia, Francisco comentou: "Eu nunca tinha sentido a dor do abandono e é a primeira vez que eu estou sentindo, me sentindo abandonado. Tô podendo sentir a dor dela no dia em que foi abandonada pela mãe. Não fomos nós que a abandonamos, foi ela quem nos abandonou”.

Por fim, refletindo sobre o que poderia ter evitado a dissolução da adoção, Lucia queixa-se da rede de apoio, indicando que as crianças precisariam receber acompanhamento psicológico nas instituições de acolhimento, antes de ir para adoção: "Ela precisava ter sido tratada antes de ter ido pra uma adoção". Além disso, reforça a necessidade de acompanhamento após a adoção: "É aquilo que eu insisto e bato em cima, não existe um apoio do governo após a adoção. Não tem nada, você não consegue nem grupo de apoio. A pós-adoção pra mim é a chave de uma adoção bem-sucedida".

\section{Discussão}

A eleição da participante Lucia para o presente estudo foi definida naturalmente, uma vez que, das quarenta e sete tentativas de se obter uma entrevista com pessoas que adotaram e desistiram da adoção, apenas essa se efetivou. A imensa maioria dos convites para a pesquisa foram respondidos com silêncio, alguns com negativas após conversas com o cônjuge, ou por não desejar reviver o sofrimento experienciado. É compreensível o desejo de não participar da pesquisa por envolver uma temática delicada, que traz sofrimento. Todavia, considerando esse número excessivo de negativas, pode-se questionar se ele não reflete também a perspectiva trazida por Muniz (2016) de que o tema da dissolução da adoção é um tabu e, quando abordado, traz consigo o desejo de condenação dos responsáveis, o que produz receio e vergonha nas pessoas que adotaram e, por diferentes motivos, experienciaram a dissolução da adoção.

A irrevogabilidade da adoção é prodigamente referida e discutida na literatura (Caires Rocha \& Mendes, 2018; Campidelli \& Bertoncini, 2018; Lunelli, Lima, \& Tomé, 2019), sendo enfatizada no artigo 39, Parágrafo $1^{\circ}$ do Estatuto da Criança e do Adolescente (ECA) (Brasil, 1990). No entanto, os casos tratados na literatura e caracterizados principalmente como "devolução" desafiam tanto a percepção de estudiosos e profissionais das mais diversas áreas envolvidas nos processos de adoção quanto o que postula a lei. A falta de previsão legal da dissolução da adoção não tem conseguido evitar que ela aconteça na prática, mas faz com que não existam estatísticas oficiais da sua ocorrência nem políticas públicas direcionadas a sua prevenção, o que leva ao questionamento sobre o quanto isso pode estar contribuindo para a invisibilidade do fenômeno e o sofrimento solitário de crianças, adotantes/pais e profissionais que a vivenciam/acompanham.

Entre as muitas causas da dissolução da adoção, a frustração das expectativas é constantemente referenciada (Ghirardi, 2008a; Levinzon, 2016, 2020; Machado 2014; Schettini et al., 2006; Souza \& Casanova, 2018). O presente estudo evidencia que Lucia já tinha a experiência de uma primeira adoção quando optou por um segundo filho, nesse caso com a expectativa de que fosse uma criança pequena. Seu desejo foi atendido pela identificação de Joaquim com esse perfil, mas a criança tinha três irmãs mais velhas, que deveriam ser adotadas 
conjuntamente. Nesse caso, cabe perguntar: Como foi a avaliação profissional para saber as condições de Lucia e Francisco em acolher um grupo de irmãos? O relato evidencia o quanto a entrevistada demonstrou-se insegura com o número de crianças e o quanto já houve algumas interrupções no processo de adoção desde essa etapa precoce. Também permite perceber posicionamentos diferentes da equipe profissional que acompanhava o caso (juiz, assistente social e psicóloga), assim como ausência de um efetivo e contínuo acompanhamento durante o período de aproximação e estágio de convivência.

Crawford (2017), Ní Chobhthaigh e Duffy (2019) e Palacios et al. (2019), em seus estudos, apontam para a necessidade de capacitação de profissionais e articulação da equipe para dar suporte às famílias por adoção, já que existem enormes demandas e grandes desafios para atender adequadamente essa população. Indicam, ainda, que o funcionamento familiar adotivo, o comportamento de pais e filhos e as relações iniciais que vão sendo desenvolvidas mediam o vínculo entre as adversidades pré-adoção e os resultados posteriores.

Além disso, mostra-se importante a preparação de pretendentes, adotantes e adotados, especialmente as crianças maiores, antes de inseri-las na família, já que elas podem ter passado por experiências marcantes de vínculos rompidos, as quais podem interferir nas novas relações familiares (Carnaúba \& Ferret, 2018; Schettini et al., 2006; Souza \& Casanova, 2018). As autoras evidenciam que dissoluções podem ocorrer por dificuldades de ambas as partes e por obstáculos que surgem no decorrer da construção de um novo vínculo. Nessa direção, questiona-se: como foi a preparação de Julia e de suas irmãs para a adoção, considerando que o desejo de Lucia e Francisco era pelo irmão menor? Como um dos aspectos que, na sua visão, poderia ter feito diferença na experiência vivenciada, Lucia destaca um atendimento psicológico a Julia na época do acolhimento, anteriormente ao ingresso na família adotiva.

$\mathrm{Na}$ continuidade do relato da história de vida, Lucia sublinha muitas mudanças, abdicando de sua profissão, mudando de cidade e, posteriormente, de país, o que implicou perda da rede de apoio e dedicação exclusiva à maternidade. Revela que, com as outras crianças, a construção de vínculo foi tranquila, diferentemente do que aconteceu em relação a Julia. Nesse caso, atribui quase totalmente à menina a responsabilidade pela dificuldade de vinculação, devido à história pregressa da garota, ao papel que assumia perante os irmãos e ao despreparo "para chamar alguém de mãe". A literatura já destaca o quanto as crianças tendem a ser culpabilizadas pelo insucesso da adoção (Levy et al., 2009; Muniz, 2016), o que precisa ser questionado na medida que pode gerar graves repercussões na trajetória de desenvolvimento delas.

Brodzinsky e Smith (2019) revelam que muitas crianças, ao serem adotadas, carregam histórico de traumas e adversidades advindos de sua família de origem, o que pode dificultar sua adaptação à nova família. Além disso, algumas características de Julia, como a idade na adoção e problemas emocionais e comportamentais, são apontadas como de risco para a dissolução da adoção (Faulkner et al., 2017; Paniagua et al., 2019; Selwyn et al., 2014; Wijedasa \& Selwyn, 2017). Todavia, a construção de vínculo é uma via de mão dupla, sendo necessário atentar para todos os envolvidos no processo. Maza (2014) destaca que é preciso que os pais por adoção tenham habilidade para lidar com problemas e flexibilidade, além de diferentes autores (Faulkner et al., 2017; Palacios et al., 2015; Selwyn et al., 2014) destacarem a importância de os profissionais envolvidos no processo de adoção estarem disponíveis e serem capazes de avaliar precocemente as dificuldades que poderão irromper.

Abrahão e Parrão (2019) e Lima, Bussolo e Oliveira (2019) argumentam que, após ser efetivada a adoção, apresentam-se aspectos psíquicos extremamente complexos, tanto para pais como para crianças/adolescentes, tendo em vista as marcas apresentadas decorrentes da história 
de cada um dos envolvidos. No entanto, poderão ser reduzidas com o apoio e acompanhamento de profissionais especializados em adoção. Enfatiza-se a importância do trabalho realizado pelos profissionais desde a preparação, mas principalmente no período pós-adoção (Borel, Santos, \& Costa, 2019; Brodzinsky \& Smith, 2019; Caires Rocha \& Mendes, 2018; Costa et al., 2019; Waid \&Alewine, 2018).

Em vários pontos da entrevista, Lucia se refere à necessidade de atenção à família no processo que se segue à efetivação da adoção, apontando deficiências do sistema de apoio psicológico no pós-adoção, principalmente quanto ao acesso a profissionais com conhecimento especializado na área. $\mathrm{Na}$ literatura internacional, pesquisas sobre dissolução indicam a necessidade de acompanhamento posterior à adoção, especialmente no período de transição para adolescência, dada a amplitude de desafios que essa exige (Maza, 2014; Paniagua et al., 2019; Rolock \& White, 2016). Corroborando essa ideia, Waid e Alewine (2018) asseguram que os serviços de apoio às famílias por adoção devem ser intensificados quando as crianças estão passando por transições de desenvolvimento, sendo o momento de maior busca por esse tipo de ajuda aquele que corresponde à passagem da infância para a adolescência, por ser um período particularmente vulnerável para algumas famílias.

Também destacando a importância do período da adolescência, Paniagua et al. (2019) realizaram um estudo com base em 69 casos de dissolução da adoção ocorridos no período de uma década em uma região da Espanha, com o objetivo de comparar características das ocorrências antes ou após a adolescência. Os resultados revelaram um perfil bem diferenciado dos casos. As adoções anteriores à adolescência foram rompidas prioritariamente no período do estágio de convivência, pois os pais tinham expectativas mais irrealistas sobre as crianças. O rompimento aconteceu de forma mais abrupta, com menos tentativas de reintegração familiar. Por sua vez, após a adolescência, a dissolução ocorreu preponderantemente depois da formalização da adoção, principalmente relacionada ao comportamento do adolescente e à presença de violência entre pais-filhos. Nesse grupo, a dissolução ocorreu de forma menos intempestiva, após tratamentos e esforços dos pais por manter a adoção, evidenciando, conforme os autores, maior comprometimento emocional na relação pais-filhos, ainda que o agravamento dos problemas tenha ocorrido na adolescência e resultado da dissolução da adoção. Os autores destacam como essencial que os profissionais envolvidos no processo não negligenciem ou subestimem os problemas apresentados nas etapas iniciais, considerando que eles podem evoluir em escalada até a adolescência e culminarem na dissolução, o que pode ser visto no caso relatado por Lucia. Também pode-se confirmar o comprometimento emocional de Lucia com Julia, manifestado pela preocupação de como ela estaria se alimentando no abrigo e de busca por informações, ainda que seja possível perceber ambivalência em relação a essa aproximação.

Frente ao que se passou com Lucia e diante do silêncio e das negativas em relação aos convites para entrevista realizados nesta pesquisa, surge o questionamento a respeito de que tipo de cuidado tem sido dispensado as pessoas que vivenciam a dissolução da adoção. Souza e Casanova (2018) sustentam que pais desistentes certamente não encontraram apoio psicológico para o enfrentamento de seus conflitos internos (idade avançada, impaciência, insegurança) e se sentirão estraçalhados: "se sentem a última pessoa, podem ficar em depressão, silenciam, se ocultam em dolorosos sofrimentos" (p. 110). Os sentimentos expressos por Lucia como vivenciados pelo casal frente à dissolução da adoção foram de impotência, fracasso e abandono, corroborando esses achados da literatura. 
Nesse sentido, cabe questionar o olhar que tem sido dado às pessoas que vivenciam a dissolução da adoção, quando a literatura preponderantemente destaca que são despreparadas e que apresentam motivos fúteis para a desistência da adoção (Borel et al., 2019; Lunelli et al., 2019). Concepção expressa inclusive na terminologia utilizada no contexto nacional, que os destaca como responsáveis pela "devolução de crianças e adolescentes", como se esses fossem um produto que não satisfez às necessidades e expectativas de quem o adquiriu (Ghirardi, 2008b; Souza \& Casanova, 2018). O rompimento da relação entre Julia e sua família, uma vez que já havia sido instituída a adoção, seria designado como "devolução". Conforme o argumento acima, Julia teria sido "devolvida" por seus pais e aqui, nesse ponto, o presente caso revela possível incompatibilidade de uso do termo "devolução". Somente adotantes podem "devolver" e ao adotado cabe ser "devolvido"? Pelo relato de Lucia, a iniciativa de retorno ao abrigo partiu de Julia, o que precisaria ser confirmado pelo ponto de vista da garota, mas que, por si só, revela uma dinâmica relacional complexa para ser reduzida a um contexto de "devolução". Por isso, propõe-se a utilização da expressão dissolução da adoção.

Estudiosos como Borel et al. (2019), Ghirardi (2008a), Levinzon (2016, 2020), Levy et al. (2009), Machado (2014), Souza e Casanova (2018), entre outros, que se ocupam desta temática, têm enfatizado que, de uma forma ou de outra, a dissolução da adoção se caracteriza como um duplo abandono, considerando que as crianças que retornam ao abrigo após adoção vivenciam uma reedição da experiência de abandono, já vivenciada inicialmente com o rompimento de vínculos com a família de origem. No caso em questão, Lucia destaca a manifestação do exmarido da sensação de eles terem sido abandonados. Verbovaya (2016) confirma que a dissolução afeta os pais em um nível psicológico, deixando-os decepcionados e irritados.

Para as crianças adotadas, a dissolução significa mais uma enorme adversidade a ser superada, além das experiências negativas anteriores que elas provavelmente já vivenciaram. Sendo assim, a dissolução das colocações adotivas afeta significativamente toda a família, demandando um olhar atento a todos os envolvidos e o planejamento de intervenções capazes de preveni-la.

\section{Considerações finais}

As características do caso de dissolução da adoção de que trata o presente artigo constitui oportunidade para discussão acerca do fenômeno da adoção e seus desdobramentos, quais sejam: a irrevogabilidade da adoção, os processos de constituição do vínculo, a importância das equipes de apoio e a aplicabilidade do termo "devolução" para os casos de dissolução. Diante da experiência relatada por Lucia, sublinham-se: maior ênfase na preparação dos adotantes e crianças/adolescentes; articulação entre os profissionais envolvidos nos processos de identificação dos perfis e aproximação entre adotantes e adotados; apoio e acompanhamento das famílias no pós-adoção e ao longo do desenvolvimento, para que as dificuldades sejam identificadas e manejadas em etapa inicial. Há necessidade, também, de estudos que possibilitem avaliar os impactos da dissolução da adoção na perspectiva de todos os envolvidos, o que fica como sugestão para futuras investigações, uma vez que teria sido relevante conhecer a experiência de Julia, considerando que a dissolução da adoção significou para ela afastamento não somente dos pais adotivos, mas também de seus irmãos. Aponta-se, ainda, a partir da vivência compartilhada por Lucia, que inexiste a possibilidade de generalização, já que cada 
caso é único. Diante das especificidades de cada processo de adoção, é fundamental acolher cada caso com abertura e flexibilidade, considerando todas as possibilidades e desdobramentos.

\section{Referências}

Abrahão, E. B., \& Parrão, J. A. O. (2019). A devolução de crianças e adolescentes no processo de adoção: a família idealizada. Anais do Encontro Toledo de Iniciação Científica, Presidente Prudente, SP, Brasil, 2019.

Araújo, M. I. (2017). A devolução de crianças na adoção tardia e a construção da maternidade. Dissertação de Mestrado, Universidade Católica de Salvador, Salvador, BA, Brasil.

Borel, E. F., Santos, R. B., \& Costa, D. (2019). Evolução da legislação brasileira no tocante à adoção e à devolução de crianças e adolescentes adotados no Brasil. Humanidades em Perspectivas, 2(1), 22-35. Recuperado de https://www.uninter.com/revistahumanidades/index.php/revista-humanidades/article/view/23

Brasil (2009). Lei Nacional da Adoção. Lei n. 12.010, de 3 de agosto de 2009. Brasilia, DF. Autor.Recuperado de http://www.planalto.gov.br/ccivil 03/ ato20072010/2009/lei/112010.htm

Brasil (1990). Estatuto da Criança e do Adolescente. Lei n. 8.069, de 13 de julho de 1990. Brasilia, DF. Autor. Recuperado de http://www.planalto.gov.br/ccivil 03/leis/18069.htm

Brodzinsky, D., \& Smith, S. L. (2019). Commentary: understanding research, policy, and practice issues in adoption instability. Research on Social Work Practice, 29(2), 185-194. doi: https://doi.org/10.1177/1049731518782647

Caires Rocha, K. S. D. C. S., \& Mendes, A. M. (2018). Adoção frustrada: a responsabilidade civil em face da devolução da criança ou adolescente. Revista da Esmam, 12(14), 19-50. Recuperado de https://revistaesmam.tjma.jus.br/index.php/esmam/article/view/6

Campidelli, L. F., \& Bertoncini, C. (2018). Análise sobre a devolução da criança e do adolescente no processo de adoção: danos psicológicos e a possibilidade de responsabilidade civil. Revista de Direito de Família e Sucessão, 4(2), 78-98. doi: http://dx.doi.org/10.26668/IndexLawJournals/2526-0227/2018.v4i2.5022

Carnaúba, G. S., \& Ferret, J. C. F. (2018). Devolução de crianças adotadas: consequências psicológicas causadas na criança que é devolvida durante o estágio de convivência. Revista Uningá, 55(3), 119-129.

Recuperado

de http://revista.uninga.br/index.php/uninga/article/view/83

Costa, D., Bortoli, D. M., \& Severo, E. (2019). Devolução de crianças e adolescentes no período pós-adoção. Humanidades em Perspectivas, 6(3), 50-58. Recuperado de https://www.uninter.com/cadernosuninter/index.php/humanidades/article/view/1191

Crawford, L. (2017). Examining post-adoption services: what adoptive families need for beneficial outcomes. (Dissertation of Master's). Catherine University, St. Paul, Minnesota, EUA. Recuperado de https://sophia.stkate.edu/msw_papers/723

Creswell, J. W., \& Clark, V. L. P. (2013). Pesquisa de métodos mistos: série métodos de pesquisa. Porto Alegre, RS: Penso.

Faulkner, M., Adkins, T., Fong, R., \& Rolock, N. (2017). Risk and protective factors for discontinuity in public adoption and guardianship: a review of the literature. Southfield, 
MI: National Quality Improvement Center for Adoption and Guardianship Support and Preservation.

Ghirardi, M. L. A. M. (2008a). A devolução de crianças e adolescentes adotivos sob a ótica psicanalítica: reedição de histórias de abandono. Dissertação de Mestrado não publicada, Universidade de São Paulo, São Paulo, SP, Brasil.

Ghirardi, M. L. A. M. (2008b). O impossível da maternidade em um caso de devolução da criança a ser adotada: interface entre a infertilidade e a feminilidade. Anais do Congresso Internacional de Psicopatologia Fundamental, São Paulo, SP, Brasil.

Junqueira, M. D. F. A. (2014). Parentalidade contemporânea: encontros e desencontros. Primórdios, 3(3), 33-44. Recuperado de http://cprj.com.br/primordios/03/03 Parentalidade_contemporanea_encontros_e desencon tros.pdf

Levinzon, G. K. (2006). Adoção (Coleção Clínica Psicanalítica). São Paulo, SP: Casa do Psicólogo.

Levinzon, G. K. (2016). Adoção e sofrimento psíquico. Psicanálise, 18(1), 57-73. Recuperado de $\quad$ http://sbpdepa.org.br/site/wp-content/uploads/2017/03/Ado $\% \mathrm{C} 3 \% \mathrm{~A} 7 \% \mathrm{C} 3 \% \mathrm{~A} 3 \mathrm{o}-\mathrm{e}-$ sofrimento-ps $\% \mathrm{C} 3 \%$ ADquico.pdf

Levinzon, G. K. (2020). Tornando-se pais: a adoção em todos os seus passos (2a ed.). São Paulo, SP: Blucher.

Levy, L., Pinho, P. G., \& Faria, M. M. (2009). "Família é muito sofrimento": um estudo de casos de "devolução" de crianças. Psico, 40(1), 58-63. Recuperado de https://revistaseletronicas.pucrs.br/ojs/index.php/revistapsico/article/view/3730

Lima, C. F. I., Bussolo, T. J., \& De Oliveira, M. A. M. (2019). Adoção e devolução de crianças. Perspectivas em Psicologia, 23(2), 103-123. Recuperado de http://www.seer.ufu.br/index.php/perspectivasempsicologia/article/view/52225

Lunelli, M., Lima, D. S., \& Tomé, M. D. P. (2019). Devolução de criança e adolescente após adoção e o olhar da justiça brasileira. Humanidades em Perspectivas, 6(3), 158-167. Recuperado https://www.uninter.com/cadernosuninter/index.php/humanidades/article/download/1200/9 $\underline{55}$

Machado, R. N. (2014). Parentalidade e filiação adotivas: o que revelam e o que ocultam as narrativas dos pais. Tese de Doutorado, Pontifícia Universidade Católica do Rio de Janeiro, Rio de Janeiro, RJ, Brasil.

Maza, P. (2014). Post-adoption instability: a national study. In S. L. Simith. Keeping the promise. The case for adoption support and preservation (pp. 51-64). New York, NY: The Donaldson Adoption Institute.

Morelli, A. B., Scorsolini-Comin, F., \& Santeiro, T. V. (2015). O "lugar" do filho adotivo na dinâmica parental: revisão integrativa de literatura. Psicologia Clínica, 27(1), 175-194. doi: https://doi.org/10.1590/0103-56652015000100010

Muniz, F. M. R. P. (2016). "Adoções" que não deram certo: o impacto da "devolução" no desenvolvimento da criança e do adolescente na perspectiva de profissionais. Dissertação de mestrado, Universidade Católica de Pernambuco, Recife, PE, Brasil.

Ní Chobhthaigh, S., \& Duffy, F. (2019). The effectiveness of psychological interventions with adoptive parents on adopted children and adolescents' outcomes: a systematic 
review. Clinical Child Psychology and Psychiatry, 24(1), 69-94. doi: https://doi.org/10.1177/1359104518786339

Nichols, M. P., \& Schwartz, R. C. (1998). Terapia familiar: conceitos e métodos. Porto Alegre, RS: Artmed.

Palacios, J., Jiménez-Morago, J. M., \& Paniagua, C. (2015). Rupturas en adopción y acogimiento familiar en Andalucía. Incidencia, factores de riesgo, procesos e implicaciones. Informe no publicado. Seville: Universidad de Sevilla.

Palacios, J., Rolock, N., Selwyn, J., \& Barbosa-Ducharne, M. (2019). Adoption breakdown: concept, research, and implications. Research on Social Work Practice, 29(2), 130-142. doi: https://doi.org/10.1177/1049731518783852

Paniagua, C., Palacios, J., \& Jiménez-Morago, J. M. (2019). Adoption breakdown and adolescence. Child \& Family Social Work, 24(4), 512-518. doi: https://doi.org/10.1111/cfs.12631

Queiroz, E. F., \& Passos, M. C. (2012). A clínica da adoção. Recife: Ed. Univ. UFPE.

Rolock, N., \& White, K. R. (2016). Post-permanency discontinuity: a longitudinal examination of outcomes for foster youth after adoption or guardianship. Children and Youth Services Review, 70, 419-427. doi: https://doi.org/10.1016/j.childyouth.2016.10.025

Rosnati, R., Ranieri, S., \& Ferrari, L. (2017). Panorama international des recherches sur les échecs d'adoption. In C. Jeannin (Ed.), Vers une plus grande competence: Apprendre des échecs de l'adoption internationalle (pp. 40-43). Genève, IT: Service Social International.

Rossato, J. G., \& Falcke, D. (2017). Devolução de crianças adotadas: uma revisão integrativa da literatura. Revista da SPAGESP, 18(1), 128-139. Recuperado de http://pepsic.bvsalud.org/scielo.php?script $=$ sci abstract\&pid $=\mathrm{S} 1677-$ 29702017000100010\&lng=pt\&nrm=iso

Santos, A. F. A. (2018). Adoções frustradas: os reflexos jurídicos da devolução de crianças e adolescentes adotados. Monografia de Graduação, Universidade Federal de Sergipe, São Cristóvão, SE, Brasil.

Schettini, S. S. M., Amazonas, M. C. L. D. A., \& Dias, C. M. D. S. B. (2006). Famílias adotivas: identidade e diferença. Psicologia em Estudo,11(2), 285-293. doi: https://doi.org/10.1590/S1413-73722006000200007

Selwyn, J., Wijedasa, D., \& Meakings, S. (2014). Beyond the adoption order: challenges, interventions and disruption. London, UK: Department for Education.

Silva, M. F. (2008). Devolvido ao remetente: uma reflexão sobre a devolução de crianças e adolescentes adotados em Florianópolis. Monografia de Graduação, Universidade Federal de Santa Catarina, Florianópolis, SC, Brasil.

Souza, H. P.; \& Casanova, R. P. S. (2018). Adoção e seus desafios. Curitiba, PR: Juruá.

Speck, S., Queiroz, E. F. D., \& Martin-Mattera, P. (2018). Desafios da clínica da adoção: devolução de crianças. Estudos de Psicanálise, (49), 181-186. Recuperado de http://pepsic.bvsalud.org/scielo.php?script=sci_arttext\&pid=S0100-34372018000100018

Verbovaya, O. (2016). Theoretical explanatory model of international adoption failure: Attachment and ecological systems perspectives. Adoption Quarterly, 19(3), 188-209. doi: https://doi.org/10.1080/10926755.2015.1113219 
Waid, J., \& Alewine, E. (2018). An exploration of family challenges and service needs during the post-adoption period. Children and Youth Services Review, 91, 213-220. doi: https://doi.org/10.1016/j.childyouth.2018.06.017

White, K. R. (2016). Placement discontinuity for older children and adolescents who exit foster care through adoption or guardianship: a systematic review. Child and Adolescent Social Work Journal, 33(4), 377-394. doi: https://doi.org/10.1007/s10560-015-0425-1

Wijedasa, D., \& Selwyn, J. (2017). Examining rates and risk factors for post-order adoption disruption in England and Wales through survival analyses. Children and Youth Services Review, 83, 179-189. doi: https://doi.org/10.1016/j.childyouth.2017.10.005

Yin, R. (2001). Estudo de caso: planejamento e métodos. Porto Alegre, RS: Bookman.

Zornig, S. M. A. J. (2010). Tornar-se pai, tornar-se mãe: o processo de construção da parentalidade. Tempo Psicanalítico, 42(2), 453-470. Recuperado de http://pepsic.bvsalud.org/scielo.php?pid=S0101-48382010000200010\&script=sci_abstract

Revisão gramatical: Catherina Coradini Rosso

E-mail: catherina.form@gmail.com

Recebido em novembro de 2020 - Aceito em outubro de 2021. 